\title{
Musings on interesting and impactful theory and research
}

\author{
Rajan Varadarajan ${ }^{1}$
}

Published online: 19 September 2016

(C) Academy of Marketing Science 2016

In his editorial on interesting and impactful research, Tellis (2016) makes a number of insightful observations and offers valuable suggestions for researchers. With the objective of fostering further debate and discussion on an important issue, in this commentary, I attempt to: (1) provide further substantiation for some of the points highlighted and guideposts offered by Tellis, by drawing attention to other supporting literature; (2) address certain other issues pertaining to potentially interesting and impactful research to complement the issues addressed by Tellis; and (3) elaborate on certain views espoused by Tellis on which I hold a different point of view.

\section{Perspectives on characteristics of good theory}

Tellis (2016) notes that a good theory is a simple explanation for a phenomenon, and the best theory is the simplest explanation for a wide set of phenomena. He further notes that simplicity is not a limitation, but a paramount virtue of a theory. In this regard, Dawkins (2008) notes that a measure of the power of a scientific theory is its explanatory ratio (the number of facts that the theory explains divided by the number of assumptions it makes in order to explain). In characterizing Darwin's theory of evolution as a powerful theory, he notes that the numerator of the explanatory ratio for the theory is large (explains all of life and its complexities) and its

Rajan Varadarajan

varadarajan@tamu.edu

1 Department of Marketing, Mays Business School at Texas A\&M University, College Station, TX 77843-4112, USA denominator spectacularly small and simple (natural selection, the non-random survival of genes in gene pools).

Also pertinent in this regard are the characteristics that Wilson (1998, p. 198) enumerates as qualities that scientists look for in theory generally, and mathematical models in particular: (1) Parsimony: the fewer the units and processes used to account for the phenomenon, the better. (2) Generality: the greater the range of phenomena covered by a model, the greater the likelihood of it being true. (3) Consilience: units and processes of a discipline that conform with solidly verified knowledge in other disciplines have proven to be consistently superior in theory and practice in comparison to units and processes that do not. (4) Predictiveness: theories that are precise in the predictions they make across many phenomena and whose predictions are easiest to test by observation and experiment endure.

In an article titled "The tyranny of simple explanations," Ball (2016) cautions that there is no easy equation between simplicity and truth. He points out that while simple and elegant theories have sometimes turned out to be wrong, simpler but less accurate theories can be more useful than complicated ones for clarifying the bare bones of an explanation. In this regard, he draws attention to the use and misuse of Occam's razor (a philosophical concept credited to a 14th-century English Franciscan friar, William of Ockham) as a tool for adjudicating between rival theories. Ball notes that Occam's razor, which is often invoked as an injunction against making more assumptions than absolutely needed, is only relevant if two competing theories predict identical results but one is simpler than the other (i.e., makes fewer assumptions). However, he notes, such situations are rarely if ever encountered in science, and that more often, the difference between rival theories is not one of fewer versus more assumptions, but different assumptions. 


\section{Destiny of theories: debunked theories, enduring theories, and the question of theory or fact}

An often espoused view is that the theories that are currently in vogue are essentially theories that have not been rejected as yet. For instance, Glaeser (2011) notes: "But we need to always remember that data and statistical tests never prove a theory. Typically, many different theories can explain almost any observed phenomenon. Data allows us only to reject a theory. The theories that survive are those that haven't been rejected yet, and that's a good reason for humility." In a similar vein, Wilson (1998) notes that scientific theories are constructed specifically to be blown apart if proved wrong, and if so destined, the sooner the better. In his editorial, Tellis (2016) also alludes to theories having a limited life span. He notes that while theories may come and go, phenomena are enduring.

Interestingly, a number of theories have endured for a long period of time. For instance, the year 2017 marks the 80th anniversary of Coase's transaction cost theory of the firm, 2015 marked the 100th anniversary of Einstein's general theory of relativity, 2009 the 150th anniversary of Darwin's theory of evolution, and 2014 the 500th anniversary of Copernicus' heliocentric theory (the handwritten unpublished version entitled the Little Commentary). Dawkins (2015) makes a case for referring to evolution as a fact, as opposed to as a theory. He notes that while to philosophers, a fact can never be more than a hypothesis on probation (a hypothesis that has withstood all attempts to falsify it, thus far), he draws attention to Gould's characterization of "fact" in science as meaning, confirmed to such a degree that it would be perverse to withhold provisional assent. In this vein, Dawkins characterizes the fact of evolution as something that has been firmly established by evidence. However, he acknowledges that scientists who speak of the fact of evolution as distinct from Darwin's hypothesis of its mechanism (natural selection) would relegate natural selection, but not evolution itself, to a Sense 2 theory (a hypothesis proposed as an explanation; see Dawkins for more on Sense 1 and Sense 2 theory).

\section{Reigning theory, rival theory, and theory lifespan in the rough-and-tumble of the academia}

In the long-run, the lifespans of competing theories are likely to be determined by their scientific merits (cumulative research evidence). That is, whether a reigning theory endures or is supplanted by a rival theory. However, in the short-run, how effectively competing theories are championed in the roughand-tumble of academia is also likely be a determining factor. In this regard, Somers (2013) quotes Bob French: "Of course, the folly of being above the fray is that you're also not a part of it. There are very few ideas in science that are so black-and- white that people say 'Oh, good God, why didn't we think of that?' Everything from plate tectonics to evolution - all those ideas, someone had to fight for them, because people didn't agree with those ideas. And if you don't participate in the fight, in the rough-and-tumble of academia, your ideas are going to end up being sidelined by ideas which are perhaps not as good, but were more ardently defended in the arena."

\section{Inspired by important and passionate about impact vs. inspired by interesting and agnostic about impact}

The works of Norman Borlaug (Nobel Peace Prize winner and father of the Green Revolution) and G. H. Hardy (an English mathematician and father of number theory) are instructive in this regard. The impetus behind Borlaug's pioneering research was the development of genetically improved high-yield, disease-resistant varieties of seeds for growing rice, wheat, corn, and other food grains to alleviate poverty and hunger in mankind. On a scale of impactful research on the wellbeing of humanity at large, few streams of research in the annals of human civilization rise to the level of Borlaug's research, which by increasing the yields of various food grains fourfold, was instrumental in alleviating hunger and poverty that afflicted hundreds of millions of people in developing and less developed countries during the last century.

However, the modern-day research university is a big tent that's home to both researchers who may be passionate about the potential impact of their research as well as those who may be agnostic. To those in the latter camp, whether a phenomenon is interesting and worthy of inquiry to them is all that may matter. Case in point, in a review of a book on cryptography, Osserman (1999) reminisces on Hardy's characterization of the great bulk of higher mathematics including number theory as useless, and Hardy's assessment of his own work as unlikely to make, directly or indirectly, for good or ill, the least difference to the amenity of the world. Osserman points out that although number theory did initially seem useless, in 1977, three mathematicians came up with an ingenious method to put it to practical use. According to Osserman, their simple but clever use of a little-known elementary result from number theory evolved into a multi-million dollar software business with millions of copies of a software program being installed on computers worldwide.

\section{Seemingly absurd and potentially impactful}

Tellis (2016) posits that while the attention that a counterintuitive premise engenders increases linearly with the strength of the refutation, persuasion or buy-in is bell-shaped. That is, up to a point, the stronger the refutation the greater the degree of buy in; however, beyond that point, refutation 
strength is likely to engender more negative than positive response leading to shock and ultimate rejection (absurd). Hence, Tellis suggests, the ideal is to strive to elicit a response of "interesting" or "fascinating" but not "absurd." Researchers may be better off being detached and dispassionate on this issue rather than being concerned about whether the strength of refutation is likely to engender a response of "absurd," and whether they should do anything about it.

Recent research on the parasitic effects of cats on humans is instructive in this regard. Research by Jaroslav Flegr, an evolutionary biologist, concerns whether a parasite carried by cats and excreted in their feces, when it creeps into the brains of humans could tweak the connections between neurons, and result in changes in the responses of humans to frightening situations (not being frightened), trust in others, outgoingness, preference for certain scents, as well as contribute to car crashes, suicides, and mental disorders such as schizophrenia. The impetus for Felgr's research was his suspicion that a single-celled parasite was subtly manipulating his personality, causing him to behave in strange, often selfdestructive ways, and reasoning that if the parasite was messing with his mind, it was also probably messing with the minds of others. In an article on Flegr's research, McAuliffe (2012) writes: "Flegr has pursued this theory for decades in relative obscurity. ... And, he believes, his views may invite deep-seated opposition. 'There is strong psychological resistance to the possibility that human behavior can be influenced by some stupid parasite,' he says. 'Nobody likes to feel like a puppet. Reviewers [of my scientific papers] may have been offended." Interestingly, after years of being ignored or discounted, Flegr's pioneering research has caught the attention of researchers in a number of fields including epidemiology, neurobiology, neuroscience, parasitology, and schizophrenia.

\section{Empirical generalizations in behavioral sciences and sample selectivity}

As pointed out by Tellis (2016), at the level of an individual research study (at the micro level), the sample being selective and not representative of the population is a pitfall that researchers should be cognizant about. Given the quest in a number of behavioral sciences for research insights that generalize to all humans (i.e., human universals), this is also a relevant issue at the macro level. In this regard, Henrich et al. (2010) contend that notwithstanding its quest for human universals, a disproportionately large body of research in the field of psychology is focused on a group of WEIRD outliers (Westernized, educated people from industrialized, rich democracies). The authors note that $68 \%$ of research subjects in a sample of hundreds of studies in leading psychology journals came from the United States, and $96 \%$ from Western industrialized nations. Of the American subjects, $67 \%$ were undergraduates studying psychology - making a randomly selected American undergraduate 4,000 times likelier to be a subject than a random non-Westerner. The criticism that generalizations about "human" traits in the field of psychology are largely based on data from a slender subpopulation also applies to a number of other fields including marketing. However, the limited funds available for pursuit of research in various behavioral sciences, including in rich and industrialized Western democracies, is a non-trivial issue.

\section{In closing: half-life of interesting and impactful research}

A pertinent issue, even in regard to impactful research on interesting phenomena is how long they are likely to be impactful. Arbesman (2012) draws a parallel between radioactive decay and the churn of knowledge in academic disciplines. He notes that while which individual fact in a discipline is likely to become obsolete cannot be predicted, the time frame in which half of the facts in a discipline are likely to become obsolete can be predicted. In regard to the half-life of scientific papers in various disciplines (the length of time during which a scientific paper loses half its influence in the field), he notes that while a study in a physics journal loses half its value in about 10 years, the rate of decay in urology is 7.1 years. He further notes that the rate of knowledge decay in the social sciences is much faster than in the physical sciences due to greater "noise" at the experimental level in research in social sciences. Arbesman refers to a study in the area of medical science dealing with hepatitis and cirrhosis, in which researchers provided a panel of experts with a set of research papers from fifty years ago and asked them which were still regarded as true and which had been refuted, or are no longer considered interesting. According to the study, Arbesman notes, every 45 years, half of the knowledge in these fields gets outdated. This brings to fore, an interesting and potentially impactful research question - the half-life of knowledge and rate of knowledge decay in various specialized areas in marketing.

\section{References}

Arbesman, S. (2012). The half-life of facts: Why everything we know has an expiration date. Penguin.

Ball, P. (2016). The tyranny of simple explanations. The Atlantic. August. Dawkins, R. (2008). Why Darwin matters. The Guardian. February 8. 
Dawkins, R. (2015). Is it a theory? Is it a law? No, it's a fact. Richarddawkins.net. November 30.

Glaeser, E. L. (2011). The role of economics in an imperfect world. The New York Times. May 10.

Henrich, J. S., Heine, J., \& Norenzayan, A. (2010). The weirdest people in the world? Behavioral and Brain Sciences, 33, 61-83.

McAuliffe, K. (2012). How your cat is making you crazy. The Atlantic. March.
Osserman, R. (1999). Cryptanalyze this. The New York Times. November 7. Somers, J. (2013). The man who would teach machines to think. The Atlantic, November.

Tellis, G. J. (2016). Interesting and impactful research: on phenomena, theroy and writing. Journal of the Academy of Marketing Science. doi: 10.1007/s11747-016-0499-0.

Wilson, E. O. (1998). Consilience: The unity of knowledge. New York: Knopf. 